\title{
Influence of different application protocols of universal adhesive system on the clinical behavior of Class I and II restorations of composite resin - a randomized and double-blind controlled clinical trial
}

Andreia Assis Carvalho*, Murillo Martins Leite, Jessica Karla Maia Zago,

Carla Aparecida Bernardes Costa Meneses Nunes, Terezinha de Jesus Esteves Barata, Gersinei Carlos de Freitas,

Érica Miranda de Torres and Lawrence Gonzaga Lopes

\begin{abstract}
Background: Multimode adhesives incorporate the versatility of adapting to various clinical situations by its capacity to be used in different protocols. This study aimed to evaluate the clinical behavior of composite resin direct restorations (Class I and II) performed with different universal dentin adhesive application protocols comparing adapted FDI and adapted USPHS criteria.
\end{abstract}

Methods: The current study is a randomized, double-blind, split-mouth, and convenience sample controlled clinical trial. The participants (age $\geq 18$ years) had restorative need of Class I and/or II due to the presence of carious lesions and/or unsatisfactory restorations in at least three dental elements. Each participant received three application protocols for Scotchbond Universal adhesive (3M ESPE), one in each tooth to be restored: $E R=$ etch-and-rinse + adhesive $(n=50)$; SEE $=$ selective enamel etch + adhesive $(n=50)$ and SE $=$ self-etch adhesive $(n=50)$. All teeth were restored in a similar way using Filtek ${ }^{\text {TM }}$ Supreme composite resin (3M ESPE). Restorations were evaluated using the adapted FDI and adapted USPHS criteria, at baseline after 7 to $21(12.02 \pm 5.68)$ days $(T 1 ; n=50$ per group) and after 12 to $20(15.8 \pm 2.7)$ months ( $(2 ; n=46$ per group) by two previously calibrated evaluators (Kappa $>0.80)$. The statistical tests were performed between groups (Friedman), intragroup (Wilcoxon), and between the criteria considering acceptable and not acceptable restorations (McNemar), $a=0.05$.

Results: A statistically significant difference was observed only for the property "superficial staining", between groups at T2 ( $p=0.01)$ for ER ( $n=13$ with score 2 or more) and SEE ( $n=3$ with score 2 or more) and intragroup for ER (T1, $n=1$ with score 2 or more; $T 2, n=13$ with score 2 or more, $p=0.001)$ and $S E(T 1, n=0$ with score 2 or more; $T 2, \mathrm{n}=8$ with score 2 or more $p=0.007$ ). For the other comparisons between groups, intragroup, and between the adapted FDI and adapted USPHS criteria, there were no statistically significant differences $(p \geq 0.05)$.

(Continued on next page)

\footnotetext{
* Correspondence: andreia.assiscarvalho@gmail.com

School of Dentistry, Federal University of Goiás, Praça Universitária, s/n,

Faculdade de Odontologia, Setor Universitário, Goiânia-GO CEP 74605220,

Brazil
}

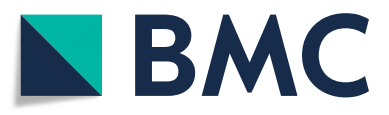

(อ) The Author(s). 2019 Open Access This article is distributed under the terms of the Creative Commons Attribution 4.0 International License (http://creativecommons.org/licenses/by/4.0/), which permits unrestricted use, distribution, and reproduction in any medium, provided you give appropriate credit to the original author(s) and the source, provide a link to the Creative Commons license, and indicate if changes were made. The Creative Commons Public Domain Dedication waiver (http://creativecommons.org/publicdomain/zero/1.0/) applies to the data made available in this article, unless otherwise stated. 
(Continued from previous page)

Conclusions: It can be concluded that the different application protocols of the universal adhesive resulted in clinically "acceptable" restorations after 15.8 \pm 2.7 months of follow-up. Adapted FDI and adapted USPHS criteria provided similar results to each other.

Trial registration.

Number in Brazilian Registry of Clinical Trials (ReBEC): RBR-9p3hdp. Registered 24 May 2015.

Keywords: Dental materials. Clinical trial. Dental bonding. Adhesives

\section{Background}

According to the form of demineralization of the dental substrate and the treatment given to the smear layer, the traditionally available adhesive systems can be divided into: etch-and-rinse (ER), self-etch (SE), and universal/ multimode $[1,2]$. ER systems profess the removal of the smear layer by etching of the dental substrate in a separate step from the application of the adhesive [1, 2]. SE adhesive systems are capable of modifying and incorporating the smear layer, simultaneously to dentin demineralization [3-5]. The universal adhesive can be used in different application modes: ER, SE, or selectice enamel etch (SEE) [6, 7]. The universal adhesive represents one type of one-step SE adhesives, and the durability and stability of bonded interfaces created by them continue to be questionable [8].

For a better comprehension of this process, it shall be understood that SE monomers are often less acidic than phosphoric acid, so that some minerals remain attached to the collagen fibers, allowing chemical bonds between the dental substrate and functional groups of the adhesive monomers [9]. Chemical bonding occurs with the interaction of functional acid monomers (carboxylic groups, phosphonic or phosphate) with hydroxyapatite crystals in dentin [10]. 10-methacryloyloxydecyl dihydrogen phosphate (10-MDP) is an example of a functional monomer that can interact with calcium ions in hydroxyapatite crystals in a process that is conducted until the formation of calcium salts of MDP (MDP-Ca salts) [10].

One of the advantages of using the universal adhesive in the clinical routine would be allowing the dental surgeon to choose the type of application protocol according to the clinical situation, optimizing the final result of the procedure [11]. However, while the development of universal adhesive systems has been an innovation in adhesive dentistry, it is questionable whether or not they are appropriate for all adhesive procedures [12]. Currently, there are only a few clinical trials that evaluate the bonding performance of universal adhesives [8]. There is still a lack of literature about these materials, with few clinical studies in Class V restorations [13-16].

It should be observed that the strength of the dentin bond is also variable according to the location of the cavity in the tooth (cervical or occlusal), and this is due to the variability of the dentinal tissue itself [17].
According to Purk et al. (2007) [18], the photopolymerizable composite resin may bond differently to the dentin, depending on the amount of cavity walls and there may be more cracks through the adhesive in the gingival wall than in the axial wall. Thus, clinical studies with universal adhesives performed in Class I and II cavities are necessary.

In this context, the clinical evaluation of restorations involves the use of criteria developed for some factors considered relevant in the clinical performance of dental restorative materials [19]. The evaluations can be judged according to different factors, among which are the USPHS (United States Public Health Service) criteria [19] and the FDI (Fédération Dentaire Internationale/ World Dental Federation), being that the latter is divided into aesthetic, functional, and biological parameters of the restorations [20]. According to the FDI criteria, the restorations can be classified into five scores: $1=$ clinically very good; $2=$ clinically good; $3=$ clinically sufficient/satisfactory; 4 = clinically unsatisfactory; and $5=$ clinically bad [20]. According to the USPHS criteria, the restorations can be classified into three scores: Alpha, Bravo and Charlie [19]. Studies comparing the clinical behavior of different bonding strategies using modified FDI and USPHS criteria have concluded that FDI criteria are more sensitive than the modified USPHS criteria for small variations in clinical outcomes of noncarious cervical lesions $[13,14,16]$.

Therefore, this work aimed to evaluate the clinical behavior of composite resin restorations performed with a universal adhesive system used in different application protocols comparing the adapted FDI and adapted USPHS criteria. Null hypotheses (is) were tested: (1) the adhesive application protocol (ER, SEE, or SE) does not influence the clinical behavior of Class I and II composite resin restorations over time, and (2) there is no difference between the adapted FDI and adapted USPHS evaluation criteria of the clinical behavior.

\section{Methods}

Study design

A randomized, double-blind and split-mouth clinical trial was conducted, which experimental design adhered to Consolidated Standards of Reporting Trials (CONSORT) 
guidelines. Clinical procedures were performed at the School of Dentistry of the Federal University of Goiás, Brazil, from June 2015 to April 2018. The research project was approved by the Research Ethics Committee (CAAE: 36829814.0.0000.5083), registered in the Brazilian Registry of Clinical Trials (ReBEC - http://www.ensaiosclinicos. gov.br; RBR-9p3hdp) and the participants signed a written informed consent form.

\section{Sample size}

The sample size calculation was based on the retention rates, postoperative sensitivity, adaptation, and marginal coloration of the Scotchbond Universal adhesive (3M ESPE, St Paul, MN, USA) for Class V restorations after 18 months [14], using $\alpha$ of 0.05 and a power of $80 \%$. Thereby, the number of 50 teeth per group was determined to detect a difference of $20 \%$ in the tested groups.

\section{Sample selection}

Inclusion criteria were age equal to or older than 18 years; clinical and radiographic need for Class I and/or II restorations in posterior permanent teeth due to the presence of carious lesions and/or unsatisfactory preexisting restoration; presence of at least three teeth (one for each adhesive protocol) to be restored per participant, which antagonistic teeth were present; and at least 20 teeth in functional occlusion.

Exclusion criteria were periodontitis; users of braces or removable orthodontic appliances; removable prosthesis wearers; signs of parafunctional habits; pregnant or lactating women; and fluorosis in the enamel.

Radiographic examination included the use of interproximal and periapical digital radiographs as auxiliary means of diagnostic for participants who presented inclusion criteria during the clinical examination. Oral hygiene guidelines were given to all study participants prior to restorative procedures.

\section{Randomization and blinding}

The randomization process was performed using manually generated tables by a member of the research group not involved in performing the clinical procedures. Details of the allocated group, including the adhesive protocol to be used and the teeth sequence to be restored, were written on sheets placed in sequentially numbered, opaque, sealed envelopes, which were opened at the time of the restorative procedure. The operator knew which type of intervention would be performed, however, the participants did not know which treatment they received for a given tooth, and the evaluators were also unaware of the adhesive protocols used (doubleblind study).
The option for split-mouth study design [21] was performed so that the same participant could receive the three adhesive protocols to be evaluated.

\section{Restorative procedures}

The clinical procedures were performed by two operators who are experts in restorative dentistry. One of them was responsible for implementing the operative procedures and the other was responsible for the restorative procedures. The basic composition of the main materials used in this study is described in Table 1 .

With absolute isolation, the operative approach of carious lesion or unsatisfactory restoration was initially performed with spherical diamond tips (KG Sorensen, Cotia, SP, Brazil), of compatible number to carious lesion or unsatisfactory restoration, in high rotation under refrigeration (Kavo, Rio de Janeiro, RJ, Brazil), and then, the carious dentin were removed with carbide bur (Maillefer, Dentsply, Rio de Janeiro RJ, Brazil) in low-speed (Contra-angle, Kavo, Rio de Janeiro, RJ, Brazil). After cavity preparation, cavity cleaning was done with $2 \%$ chlorhexidine solution (Reymer from Brazil, Aparecida de Goiânia, GO, Brazil) with sterile cotton ball for 1 $\min$.

Cavities considered very deep, the protection of the dentinopulpar complex was done with hydroxide of calcium cement (Hydro C, Dentsply, Rio de Janeiro RJ, Brazil) associated with resin-modified glass ionomer cement (Ionoseal, Voco, Cuxhaven, Germany), lining the bottom wall only. Deep cavities, the resinmodified glass ionomer cement was used. For medium or shallow depth cavities the adhesive protocols were applied directly. The Scotchbond Universal adhesive system (3M ESPE, St Paul, MN, USA) was applied to the tooth surface according to the drawn protocol, as detailed in Table 2 .

The restorations were made with Filtek $^{\text {TM }}$ Supreme composite resin (3 M ESPE, St Paul, MN, USA) in the incremental oblique technique. Each increment was photocured for $20 \mathrm{~s}$ and a final polymerization of $40 \mathrm{~s}$ was done. Immediate finishing of the restorations was performed with fine diamond tips (KG Sorensen) and/or scalpel blades (Lamedid Comercial \& Serviços Ltda, Barueri, SP, Brazil), after removal of absolute isolation and occlusal adjustment. The mediate finishing and polishing were done with silicone rubber tips (FlexiCups \& FlexiPoints, Cosmedent, Chicago, IL, USA) in the medium (blue) and superfine (pink) granulations and felt disc (Diamond, FGM, Joinville, SC, Brazil) with diamond paste (Diamond Excel, FGM,, Joinville, SC, Brazil) at the first evaluation performed. 
Table 1 Composition of the main materials used in this study informed by the manufacturers

\begin{tabular}{|c|c|c|c|}
\hline Material & Manufacturer & Lot & Composition* \\
\hline $\begin{array}{l}\text { Condac } 37 \\
\text { (Joinville, SC, Brazil) }\end{array}$ & FGM & 090715 & 37\% Phosphoric acid, thickeners. \\
\hline $\begin{array}{l}\text { Filtek }^{\text {TM }} \text { Supreme } \\
\text { (St Paul, MN, USA) }\end{array}$ & $3 \mathrm{M} \mathrm{ESPE}$ & $\begin{array}{l}\text { N595157 (color B2E) } \\
176149 \\
\text { (color B2B) }\end{array}$ & $\begin{array}{l}\text { Bis-GMA, UDMA, TEGDMA, Bis-EMA, non-agglomerated silica, } \\
\text { non-agglomerated and agglomerated zirconia, and aggregated } \\
\text { particles of zirconia/silica. }\end{array}$ \\
\hline $\begin{array}{l}\text { Scotchbond Universal } \\
\text { Adhesive } \\
\text { (St Paul, MN, USA) }\end{array}$ & $3 \mathrm{M} \mathrm{ESPE}$ & 565520 & $\begin{array}{l}\text { HEMA, MDP (10-methacryloyloxydecamethylene phosphoric acid), } \\
\text { phosphate monomer, dimethacrylate, hydroxyethyl methacrylate, } \\
\text { copolymer of polyalkanoic acid methacrylate, ethanol, water, initiators } \\
\text { and silane. }\end{array}$ \\
\hline
\end{tabular}

*According to information from the manufacturers

\section{Clinical evaluation}

The first evaluation (T1) was performed 7 to 21 (12.02 \pm 5.68) days after the restoration and, the second evaluation (T2) was performed after 12 to 20 months (15.8 \pm 2.7) of monitoring. The evaluations were performed by two properly calibrated evaluators who were not involved with the restorative procedures. Excellent interexaminer agreement was obtained for all the criteria under analysis (Kappa>0.80). Restorations were evaluated using the adapted USPHS (Table 3) [19] and adapted FDI (Table 4) criteria [20]. To evaluate the postoperative sensitivity of the teeth under analysis, air jets were applied for $10 \mathrm{~s}$ with the triple syringe $2 \mathrm{~cm}$ from the occlusal surface $[13,14,20]$, and the participant was asked if there was sensitivity caused by the air jet or if there was postoperative pain at some other time prior to the evaluation. Both examiners evaluated the restorations independently, and in the absence of agreement during the evaluations, consensus was sought before dispensing the participant.

The scores were dichotomized as "acceptable" for restorations that did not require intervention

Table 2 Clinical protocol of adhesive application in the three groups tested

\begin{tabular}{|c|c|}
\hline Technique & Clinical sequence \\
\hline Etch-and-rinse (ER) & $\begin{array}{l}\text { - Total acid etching for } 30 \text { s in enamel and } 15 \text { s in } \\
\text { dentin; } \\
\text { - Abundant washing for } 10 \text { s with water jet and } \\
\text { removal of humidity excess with absorbent paper; } \\
\text { - Application of the adhesive for } 20 \text { s; } \\
\text { - Air jet for } 5 \text { s; } \\
\text { - Photopolymerization for } 20 \text { s. }\end{array}$ \\
\hline $\begin{array}{l}\text { Selective Enamel } \\
\text { Etch (SEE) }\end{array}$ & $\begin{array}{l}\text { - Selective acid etching in enamel for } 30 \text { s; } \\
\text { - Abundant washing for } 10 \text { s with water jet and } \\
\text { removal of humidity excess with absorbent paper; } \\
\text { - Application of the adhesive for } 20 \text { s; } \\
\text { - Air jet for } 5 \text { s; } \\
\text { - Photopolymerization for } 20 \text { s. }\end{array}$ \\
\hline Self-Etch (SE) & $\begin{array}{l}\text { - Application of the adhesive for } 20 \text { s; } \\
\text { - Air jet for } 5 \text { s; } \\
\text { - Photopolymerization for } 20 \text { s. }\end{array}$ \\
\hline
\end{tabular}

(clinically very good, clinically good, clinically sufficient/satisfactory, Alpha and Bravo) and "not acceptable" (clinically unsatisfactory, clinically bad, and Charlie) for those that needed repair or replacement [14]. To compare the adapted FDI and adapted USPHS criteria, considering the "acceptable" and "not acceptable" restorations, the properties of each criterion that could be compared were separated: adapted FDI (marginal staining, material fracture and retention, marginal adaptation, postoperative hypersensitivity and dental vitality, and recurrence of caries, erosion, or abfraction) and adapted USPHS (marginal discoloration, retention, fracture, marginal adaptation, postoperative sensitivity, and recurrence of caries).

\section{Data analysis}

Statistical analysis followed the CONSORT protocol, considering the intention to treat, including all randomized participants and including those who did not participate in the evaluation appointments. Descriptive analysis was performed for the evaluated criteria. The Friedman test was used for the comparison between groups (ER, SEE, and SE) at T1 and T2. The Wilcoxon test was used for the intragroup comparison (i.e., each group between the times T1 and T2). The McNemar test was used for the comparison between the adapted FDI and adapted USPHS criteria considering acceptable and not acceptable restorations. All statistical tests were performed with SPSS software version 24 (IBM SPSS Statistics, Chicago IL, USA) at a significance level of $5 \%(\alpha=0.05)$.

\section{Results}

Initially, 95 participants were evaluated. After screening, a final sample consisted of 35 subjects, accounting for total of 150 restorations (Fig. 1). Data corresponding to participants and to restored teeth are show in Table 5. The majority of participants 
Table 3 The adapted USPHS criteria with their categories and grading

\begin{tabular}{lll}
\hline Categories & Grading & "Decision" \\
Marginal discoloration & 1. Alpha (clinically ideal) & 1. Acceptable (1, 2) \\
Fracture & 2. Bravo (showing minor deviations from the ideal, nevertheless acceptable - except & 2. Not acceptable (3) \\
Retention & 3. Charlie (should be replaced to avoid future damage or requiring immediate \\
Marginal integrity & replacement) & \\
Postoperative sensitivity & & \\
Recurrence of caries &
\end{tabular}

were female (60\%), 20-29 years old (77\%), and the restored teeth were mainly molars $(81 \%)$ with Class I type cavities (64\%).

Restorations were evaluated using the adapted FDI and adapted USPHS criteria 7 to $21(12.02 \pm 5.68)$ days after the restoration ( $\mathrm{T} 1 ; \mathrm{n}=50$ per group) and after 12 to $20(15.8 \pm 2.7)$ months $(\mathrm{T} 2 ; \mathrm{n}=46$ per group) by two previously calibrated evaluators (Kappa $>0.80$ ). The data obtained during the two-time evaluations (T1 and T2) are summarized in Table 6 (adapted USPHS criteria) and Table 7 (adapted FDI criteria).

For the "surface staining" property, a significant difference was observed at T2 between groups ER ( $\mathrm{n}=13$ with score 2 or more) and $\operatorname{SEE}(\mathrm{n}=3$ with score 2 or more; $p=0.01$ ) and intragroup for ER (T1, $\mathrm{n}=1$ with score 2 or more; $\mathrm{T} 2, \mathrm{n}=13$ with score 2 or more; $p=0.001$ ) and $\mathrm{SE}(\mathrm{T} 1, \mathrm{n}=0$ with score 2 or more; $\mathrm{T} 2, \mathrm{n}=8$ with score 2 or more; $p=0.007)$. For the other comparisons between groups and intragroup, there were no significant differences $(p \geq 0.05)$.

In each group, postoperative sensitivity (initial assessment) was reported for three restored teeth, with "clinically good" (adapted FDI criteria) and "Charlie" (adapted USPHS criteria) scores. It is noteworthy that one participant reported postoperative sensitivity after the restorations with the three adhesive protocols tested. In the T2 assessment, no participant reported pain sensitivity in the period.

There was no significant difference when the adapted FDI and adapted USPHS criteria were compared $(\mathrm{p} \geq$ $0.05)$, with "acceptable" restorations in adapted FDI (ER $\mathrm{n}=44$, SEE $\mathrm{n}=46$, and SE $\mathrm{n}=46$ ) and in adapted USPHS (ER $n=46$, SEE $n=46$, and SE $n=46$ ) after $15.8 \pm 2.7$ months of follow-up.

\section{Discussion}

The present study makes an important contribution to the literature on universal adhesive systems since it was performed in Class I and II cavities of permanent teeth, which differs from the studies of Mena-Serrano et al. (2013) [13], Perdigão et al. (2014) [14], Lawson et al. (2015) [15], and Lopes et al. (2016) [16] performed on Class V restorations. Considering that the most important parameter for evaluating the performance of an

Table 4 The adapted FDI criteria with their categories and grading

\begin{tabular}{|c|c|c|c|}
\hline Categories & Sub-categories & Grading & "Decision" \\
\hline A. Aesthetic properties & $\begin{array}{l}\text { 1. Surface lustre } \\
\text { 2. Staining } \\
\text { a. surface b. margin } \\
\text { 3. Color match and translucency } \\
\text { 4. Esthetic anatomical form }\end{array}$ & \multirow{2}{*}{$\begin{array}{l}\text { 1. Clinically excellent/very good } \\
\text { 2. Clinically good } \\
\text { 3. Clinically sufficient/satisfactory (minor } \\
\text { shortcomings, no } \\
\text { unacceptable effects but not adjustable } \\
\text { without damage } \\
\text { to the tooth) } \\
\text { 4. Clinically unsatisfactory/(but reparable) } \\
\text { 5. Clinically poor (replacement necessary) }\end{array}$} & $\begin{array}{l}\text { 1. Acceptable }(1,2,3) \\
\text { 2. Not acceptable }(4,5)\end{array}$ \\
\hline B. Functional properties & $\begin{array}{l}\text { 5. Fracture of material and retention } \\
\text { 6. Marginal adaptation } \\
\text { 7. Occlusal contour and wear } \\
\text { a) qualitatively b) quantitatively } \\
\text { 8. Approximal anatomical form } \\
\text { a. contact point b. contour } \\
\text { 9. Radiographic examination (when applicable) } \\
\text { 10. Patient's view }\end{array}$ & & \\
\hline C. Biological properties & $\begin{array}{l}\text { 11. Postoperative (hyper-)sensitivity and tooth } \\
\text { vitality } \\
\text { 12. Recurrence of caries (CAR), erosion, abfraction } \\
\text { 13. Tooth integrity (enamel cracks, tooth fractures) } \\
\text { 14. Periodontal response (always compared to a } \\
\text { reference tooth) } \\
\text { 15. Adjacent mucosa } \\
\text { 16 Oral and general health }\end{array}$ & & \\
\hline
\end{tabular}




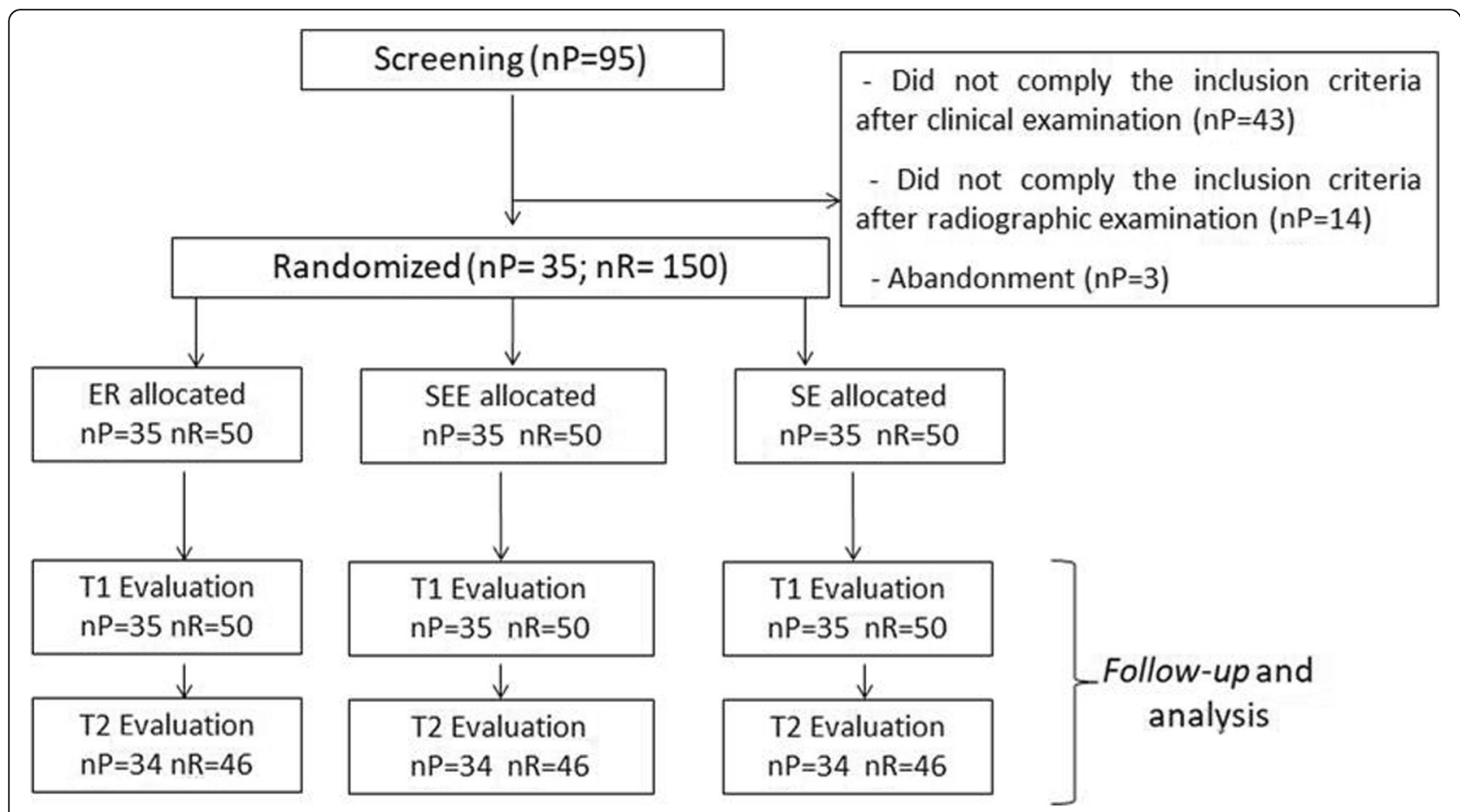

Fig. 1 Characterization of the participants of the study (nP- number of Participants; nR- number of Restorations; ER- Etch-and-rise; SEE- Selective Enamel Etch; SE- Self-Etch; T1- first evaluation; T2- second evaluation)

adhesive system is the retention [16], these studies justified the evaluation of Class V noncarious cervical lesions [13-16]. Nevertheless, the location factors of the cavities and type of masticatory forces could also influence the maintenance of the adhesive interface $[17,22]$, which highlights the importance of the evaluation performed here in Class I and II cavities.

Additionally, another factor that could interfere with the adhesive quality would be cavity cleaning after completion of the cavity preparation. In this study, $2 \%$ chlorhexidine solution was used before acid etching in the ER and SEE groups and prior to the application of the adhesive in the SE group, in order to disinfect the dentin surface, remove microorganisms, and minimize the possibility of recurrence of dental cavity [23]. However, chlorhexidine can also be used after etching, to minimize degradation by the metalloproteinases of collagen matrices that are incompletely infiltrated by the adhesive system [24]. There is no consensus in the literature concerning the efficacy of chlorhexidine use when applying SE adhesives or even when or how the chlorhexidine solution should be applied [25-27]. A recent clinical study with 36-month follow-up showed that cavity pre-treatment with chlorhexidine for inhibition of hybrid layer degradation does not add any beneficial effect to the clinical performance of restorations [28]. However, other laboratory studies have reported that for cavity cleaning prior to etching, chlorhexidine showed no significant change in microtensile bond strength of adhesive, even when the SE application mode was used [25, 29, 30]. Therefore, in the present work the option was to perform its prior

Table 5 Distribution of participants and restored teeth

\begin{tabular}{|c|c|c|c|c|c|c|c|c|c|c|c|c|c|c|}
\hline \multirow[t]{2}{*}{ Groups } & \multicolumn{2}{|c|}{ Gender } & \multicolumn{2}{|c|}{ Age (years) } & \multicolumn{2}{|c|}{ Tooth } & \multicolumn{2}{|c|}{ Arcade distribution } & \multicolumn{2}{|c|}{ Type of preparation } & \multicolumn{4}{|c|}{ Cavity Depth } \\
\hline & $\bar{M}$ & $\mathrm{~F}$ & $20-29$ & $30-50$ & $\overline{P M}$ & M & Jaw & Mand & I & $\|$ & $S$ & M & $\mathrm{D}$ & VD \\
\hline$\overline{E R}$ & 14 & 21 & 27 & 8 & 10 & 40 & 33 & 17 & 34 & 16 & 15 & 4 & 16 & 15 \\
\hline SEE & & & & & 8 & 42 & 29 & 21 & 30 & 20 & 19 & 1 & 18 & 12 \\
\hline SE & & & & & 11 & 39 & 26 & 24 & 32 & 18 & 26 & 6 & 11 & 7 \\
\hline A Frea & 14 & 21 & 27 & 8 & 29 & 121 & 88 & 62 & 96 & 54 & 60 & 11 & 45 & 34 \\
\hline R Freq & $40 \%$ & $60 \%$ & $77 \%$ & $23 \%$ & $19 \%$ & $81 \%$ & $58 \%$ & $42 \%$ & $64 \%$ & $36 \%$ & $40 \%$ & $7 \%$ & $30 \%$ & $23 \%$ \\
\hline
\end{tabular}

Abbreviations: $E R$ - Etch-and-rinse; SEE- Selective Enamel Etch; $S E$ - Self-Etch; $A$ Freq-Absolute frequency; $R$ Freq- relative frequency; $M$ - male; $F$ - female; $P M$ - premolar; $M$ - molar; Jaw- jaw; Mand- mandible; I- Class I; II- Class II; S- shallow; M- medium; D- deep; VD- very deep 
Table 6 Number of restorations evaluated, for each experimental group, classified according to the adapted USPHS criteria at T1 and $\mathrm{T} 2$ times

\begin{tabular}{|c|c|c|c|c|c|c|c|c|}
\hline & \multirow[t]{2}{*}{ Scores } & \multirow[t]{2}{*}{ "Decision" } & \multicolumn{3}{|l|}{$\mathrm{T} 1$} & \multicolumn{3}{|l|}{$\mathrm{T} 2$} \\
\hline & & & ER & SEE & SE & ER & SEE & SE \\
\hline \multirow[t]{3}{*}{ Marginal staining } & Alpha & Acceptable & 50 & 50 & 50 & 42 & 42 & 42 \\
\hline & Bravo & & - & - & - & 4 & 4 & 4 \\
\hline & Charlie & Not acceptable & - & - & - & - & - & - \\
\hline \multirow[t]{3}{*}{ Fracture } & Alpha & Acceptable & 50 & 49 & 50 & 46 & 46 & 45 \\
\hline & Bravo & & - & - & - & - & - & 1 \\
\hline & Charlie & Not acceptable & - & 1 & - & - & - & - \\
\hline \multirow[t]{3}{*}{ Retention } & Alpha & Acceptable & 50 & 50 & 50 & 46 & 46 & 46 \\
\hline & Bravo & & - & - & - & - & - & - \\
\hline & Charlie & Not acceptable & - & - & - & - & - & - \\
\hline \multirow[t]{3}{*}{ Marginal adaptation } & Alpha & Acceptable & 50 & 50 & 49 & 45 & 44 & 45 \\
\hline & Bravo & & - & - & 1 & 1 & 2 & 1 \\
\hline & Charlie & Not acceptable & - & - & - & - & - & - \\
\hline \multirow[t]{3}{*}{ Postoperative sensitivity } & Alpha & Acceptable & 47 & 47 & 47 & 46 & 46 & 46 \\
\hline & Bravo & & - & - & - & - & - & - \\
\hline & Charlie & Not acceptable & $3^{a, b, c}$ & $3^{d, e, f}$ & $3^{g, h, i}$ & - & - & - \\
\hline \multirow[t]{3}{*}{ Recurrence of caries } & Alpha & Acceptable & 50 & 50 & 50 & 46 & 46 & 46 \\
\hline & Bravo & & - & - & - & - & - & - \\
\hline & Charlie & Not acceptable & - & - & - & - & - & - \\
\hline
\end{tabular}

Abbreviations T1- first evaluation; T2- second evaluation; ER- Etch-and-rinse; SEE- Selective Enamel Etch; SE- Self-Etch. Letters overwritten: a.patient 29 tooth 16; b.patient 39 tooth 17; c.patient 46 tooth 36; d.patient 28 tooth 15; e.patient 39 tooth 36; f. patient 48 tooth 36; g. patient 8 tooth 16; h.patient 39 tooth 37; i.patient 49 tooth 46

application to the use of the adhesive system independently of its protocol.

In this context, although in the present study the application of the adhesive in a single layer was used, as indicated by the manufacturer, the possibility of its use in two layers is reported [31], in order to to enhance the bond strength. A laboratory work performed by Fujiwara et al. (2018) [31], the application of an universal adhesives in two layers improved the adhesive quality when compared to the application in a single layer. According to the authors of the study, this result may be related to the possibility of the double application protocol producing a more uniform adhesive layer and compensating for possible defects of single application [31]. This may be an important point of discussion for other long-term longitudinal follow-up clinical trials.

Based on the results obtained in this study, the first null hypothesis that "the adhesive application protocol (ER, SEE or SE) does not influence the clinical behavior of Class I and II composite restorations over time" had to be accepted, since the clinical behavior of composite resin restorations was similar, resulting in clinically acceptable restorations after $15.8 \pm 2.7$ months of follow-up, independently of the different application protocols of the universal adhesive (ER,
SEE, and SE). Similar results to those reported by Mena-Serrano et al. (2013) [13] and Perdigão et al. (2014) [14] were obtained. These studies demonstrated that the clinical behavior of the Scotchbond Universal adhesive used in the form of SEE and SE, in Class $\mathrm{V}$ restorations, did not depend on the adhesive protocol tested in clinical follow-up of 6 and 18 months, respectively. These data may be related to the short period of clinical evaluation of these studies (6 and 18 months), which was similar to the present study $(15.8 \pm 2.7$ months). In a study by Loguercio et al. (2015) [32], in 36 months of evaluation, there were signs of degradation when the universal adhesive was applied in the SE mode. Therefore, the restorations need to be re-evaluated after a long follow-up period (4-5 years) with the aim of confirming the results [33]. For Cuevas-Suarez et al., 2019 [8], the published data from the clinical trials suggested that the clinical performance of the universal adhesive did not depend on the bonding strategy in up to 36 months of follow-up.

Although statistically significant differences were observed for the surface staining property between $\mathrm{T} 1$ and T2 for the ER and SE groups and between ER and SEE techniques at $\mathrm{T} 2$, the scores remained within the 
Table 7 Number of restorations evaluated, for each experimental group, classified according to the adapted FDI criteria at T1 and T2 times

\begin{tabular}{|c|c|c|c|c|c|c|c|c|c|c|c|c|c|c|c|c|c|}
\hline & $\mathrm{D}$ & * & T1 & & & $\mathrm{T} 2$ & & & & $\mathrm{D}$ & * & $\mathrm{T} 1$ & & & $\mathrm{~T} 2$ & & \\
\hline & & & ER & SEE & SE & ER & SEE & SE & & & & ER & SEE & SE & $\mathrm{ER}$ & SEE & SE \\
\hline Surface lustre & A & 1 & 50 & 50 & 49 & 45 & 46 & 44 & Approximal anatomical form contact point & A & 1 & 14 & 19 & 16 & 11 & 14 & 12 \\
\hline & & 2 & & - & 1 & 1 & - & 2 & $(\mathrm{nR}$ Class $\|=54)$ & & & - & - & - & - & 1 & - \\
\hline & & 3 & - & - & - & - & - & - & & & 3 & 2 & 1 & 2 & 3 & 2 & 4 \\
\hline & NA & 4 & & - & - & - & - & - & & NA & & - & - & - & - & - & - \\
\hline & & 5 & & - & - & - & - & - & & & 5 & - & - & - & - & - & - \\
\hline Staining surface & A & 1 & 49 & 50 & 50 & 33 & 43 & 38 & Approximal anatomical form contour & A & 1 & 15 & 20 & 16 & 13 & 16 & 14 \\
\hline & & 2 & 1 & - & - & 10 & 2 & 7 & $(\mathrm{nR}$ Class $\|=54)$ & & 2 & 1 & - & 2 & 1 & 1 & 2 \\
\hline & & 3 & - & - & - & 2 & 1 & 1 & & & & - & - & - & - & - & - \\
\hline & NA & 4. & & - & - & $1^{\mathrm{a}}$ & - & - & & NA & 4 & - & - & - & - & - & - \\
\hline & & 5 & & - & - & - & - & - & & & & - & - & - & - & - & - \\
\hline Staining margin & A & 1 & 50 & 50 & 49 & 42 & 42 & 42 & Patient's view & A & 1 & 50 & 50 & 49 & 46 & 46 & 46 \\
\hline & & 2 & & - & 1 & 3 & 4 & 3 & & & & - & - & 1 & - & - & - \\
\hline & & 3 & - & - & - & 1 & - & 1 & & & & - & - & - & - & - & - \\
\hline & NA & 4. & & - & - & - & - & - & & NA & & - & - & - & - & - & - \\
\hline & & 5 & & - & - & - & - & - & & & & - & - & - & - & - & - \\
\hline Color match and & A & 1 & 47 & 46 & 46 & 42 & 41 & 41 & Postoperative (hyper-)sensitivity and tooth & A & 1 & 47 & 47 & 47 & 45 & 46 & 46 \\
\hline & & 2 & 2 & 4 & 4 & 2 & 4 & 4 & & & 2 & 3 & 3 & 3 & 1 & - & - \\
\hline & & 3 & 1 & - & - & 1 & 1 & 1 & & & & - & - & - & - & - & - \\
\hline & NA & 4 & - & - & - & $1^{\mathrm{a}}$ & - & - & & NA & & - & - & - & - & - & - \\
\hline & & 5 & & - & - & - & - & - & & & & - & - & - & - & - & - \\
\hline Esthetic anatomical form & A & 1 & 49 & 47 & 47 & 45 & 42 & 43 & Recurrence of caries (CAR), erosion, abfraction & A & 1 & 50 & 50 & 50 & 46 & 46 & 46 \\
\hline & & 2 & 1 & 3 & 3 & 1 & 4 & 3 & & & & - & - & - & - & - & - \\
\hline & & 3 & - & - & - & - & - & - & & & & - & - & - & - & - & - \\
\hline & NA & 4. & - & - & - & - & - & - & & NA & & - & - & - & - & - & - \\
\hline & & 5 & & - & - & - & - & - & & & & - & - & - & - & - & - \\
\hline Fracture of material & A & 1 & 50 & 49 & 50 & 46 & 46 & 45 & Tooth integrity (enamel cracks, tooth fractures) & A & 1 & 50 & 50 & 50 & 46 & 46 & 46 \\
\hline & & 2 & & 1 & - & - & - & 1 & & & & - & - & - & - & - & - \\
\hline & & 3 & - & - & - & - & - & - & & & & - & - & - & - & - & - \\
\hline & NA & 4. & - & - & - & - & - & - & & NA & & - & - & - & - & - & - \\
\hline & & 5 & & - & - & - & - & - & & & & - & - & - & - & - & - \\
\hline Marginal adaptation & A & 1 & 50 & 50 & 49 & 45 & 44 & 45 & Periodontal response & A & 1 & 16 & 20 & 18 & 14 & 17 & 16 \\
\hline & & 2 & - & - & 1 & 1 & 1 & 1 & & & & - & - & - & - & - & - \\
\hline & & 3 & - & - & - & - & 1 & - & & & & - & - & - & - & - & - \\
\hline & NA & 4 & & - & - & - & - & - & & NA & & - & - & - & - & - & - \\
\hline & & 5 & & - & - & - & - & - & & & & - & - & - & - & - & - \\
\hline Occlusal contour and & A & 1 & 48 & 50 & 49 & 44 & 45 & 45 & Adjacent mucosa & A & 1 & 50 & 50 & 50 & 46 & 46 & 46 \\
\hline & & 2 & 2 & - & 1 & 1 & 1 & 1 & & & & - & - & - & - & - & - \\
\hline & & 3 & & - & - & - & - & - & & & & - & - & - & - & - & - \\
\hline & NA & 4. & & - & - & $1^{b}$ & - & - & & NA & & - & - & - & - & - & - \\
\hline & & 5 & & - & - & - & - & - & & & & - & - & - & - & - & - \\
\hline $\begin{array}{l}\text { Occlusal contour and } \\
\text { wear (qtt) }\end{array}$ & A & 1 & 49 & 50 & 50 & 45 & 46 & 46 & Oral and general health & A & 1 & 50 & 50 & 50 & 46 & 46 & 46 \\
\hline & & 2 & 1 & - & - & 1 & - & - & & & 2 & - & - & - & - & - & - \\
\hline
\end{tabular}


Table 7 Number of restorations evaluated, for each experimental group, classified according to the adapted FDI criteria at T1 and T2 times (Continued)

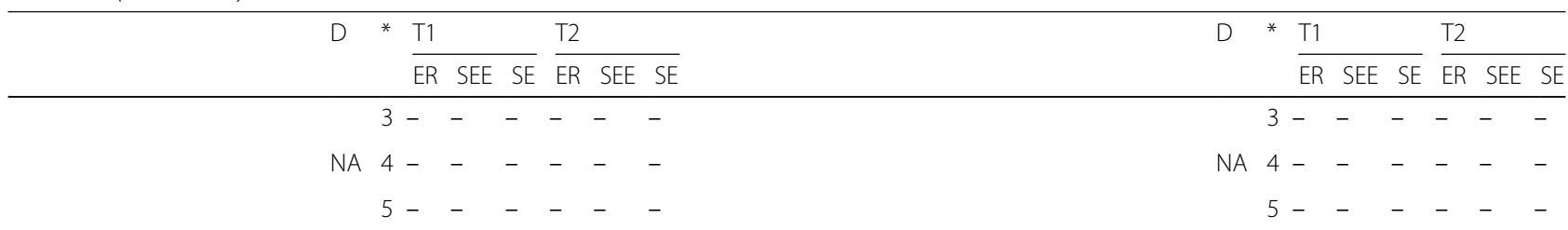

Abbreviations: $D$ - Decision; A- Acceptable; NA- Not acceptable; T1- first evaluation; T2- second evaluation; ER- Etch-and-rinse; SEE- Selective Enamel Etch; SE- SelfEtch. NA- not applicable, $n R$ - number of restorations. * Scores: 1-Clinically very good; 2- Clinically good; 3- Clinically sufficient/satisfactory; 4 - Clinically unsatisfactory; 5- Clinically bad. Letters overwritten: a.patient 1 tooth 47; b.patient 21 tooth 26

clinically acceptable range. Possibly the observed surface staining was related to oral hygiene and eating habits of the participants, which was similarly observed by other authors [34, 35].

On the other hand, Lawson et al. (2015) [15], in an evaluation after 24 months, tested the Scotchbond Universal in the ER and SE technique and the Scotchbond MultiPurpose (3 M ESPE) (ER) in Class V restoration and concluded that both tested adhesives deteriorated in relation to the adaptation and marginal discoloration. The authors also affirmed that Scotchbond Universal in the SE technique and Scotchbond Multi-Purpose presented similar clinical behavior, however, they stated that Scotchbond Universal with ER had the best results [15].

With the increase of the clinical evaluation period to 60 months, Baracco et al. (2016) [36] observed more frequent and severe marginal staining in Class I and Class II restorations when they tested the SE adhesive protocol (Adper Scotchbond SE and P90, 3 M ESPE) compared to the ER protocol (Adper Scotchbond XT, $3 \mathrm{M}$ ESPE), as well as the presence of marginal adaptation deterioration in all groups according to the adhesive systems tested. Van Dijken and Pallesen (2017) [37], after 6 years of evaluation of Class II restorations, found failures related to fracture and recurrence of dental caries when comparing a three-step ER application mode adhesive system (cmf-els, Saremco AG) and an SE without HEMA (AdheSe One $F$, Ivoclar Vivadent). The failures corresponded to $11.4 \%$ of restorations with prior acid etching and to $20 \%$ in restorations with SE adhesive [37]. The authors inferred that the fracture of the restorations was related to the extension of the restorations [37]. In the present study, a case of fracture of the restoration was observed in the initial evaluation, which also suggests that the cause is due, probably, to the extension of the restoration. In in vitro study of Jacker-Guhr et al. (2019) [38], cohesive fractures were observed for ER, mainly in the enamel, probably due to higher bond strength using universal adhesives after additional phosphoric acid etching.

On the other hand, the present clinical trial differs from the studies of Mena-Serrano et al. (2003) [13], Perdigão et al. (2014) [14] and Loguercio et al. (2018) [33] in which the deterioration of the marginal adaptation of the restorations with the use of MDP universal adhesive was observed after 6 and 18 months of clinical evaluation, both for the adhesive protocol with ER and SE application modes. This difference may be related to the incidence of masticatory forces and complexity of the restorations, once the restorations were performed in Class I and II cavities, which is different from the cited works in which the restorations were performed in Class V cavities.

In a follow-up period of 18 months, Perdigão et al. (2014) [14] reported a $2.5 \%$ loss of retention in Class V restorations, and the universal adhesive protocol did not influence the loss of retention. In the 24-month followup of Class V restorations, retention rates of 87.6, 94.9, and $100 \%$ were reported for Scotchbond Multi-Purpose (ER), Scotchbond Universal in the SE application mode, and Scotchbond Universal with ER, respectively [15]. They concluded that Scotchbond Universal, in the SE and ER application mode, was similar to or better than Scotchbond Multi-Purpose [15]. In the present study, independently of the adhesive protocol applied, $100 \%$ retention of all the performed restorations was observed. This result should probably also be related to the location and type of the restorations (Class I and II). Although there was still no difference between the adhesive protocols, a systematic review showed that the enamel bond strength of universal adhesive is improved with prior phosphoric acid etching (SEE) [39]. SEE followed by the application of a mild universal adhesive currently appears to be the best choice to effectively achieve a durable bond to tooth tissues [8]. However, this effect was not evident for dentin with the use of mild adhesive with the ER [39].

In relation to postoperative sensitivity, in the present study there were no statistically significant differences between the groups, nor was there a relationship between postoperative sensitivity and cavity depth (47\% shallow and medium $/ 53 \%$ deep and very deep). The teeth that presented sensitivity at the baseline were classified with a "Charlie" score, since for the USPHS criterion there is no "Bravo" score for this criterion [19]. Thus, the restorations are classified as "Alpha" for no reports of postoperative sensitivity 
or "Charlie" for when there is a complaint. These patients were followed up, observing a progressive regression of sensitivity not requiring intervention. In the T2 evaluation, no provoked sensitivity was observed in all restored teeth. These results are in agreement with other works in the literature using the same adhesive system in the different etching protocols [13-15] and with other adhesive systems also in the mode with ER and SE [37, 40].

To compare the criteria, the properties evaluated were dichotomized as "acceptable" and "not acceptable", similar to other studies $[13,14]$. As there were no statistically significant differences for the comparisons between the adapted FDI and adapted USPHS criteria, the second null hypothesis that "there is no difference between the adapted FDI and adapted USPHS evaluation criteria of the clinical behavior" was also accepted. The USPHS and FDI clinical evaluation criteria are described in previous studies, such as the FDI being more sensitive than the USPHS in the "marginal adaptation" parameter [13, 14]. However, the option to maintain both criteria is to allow the comparison of results with studies that used only one of the criteria [16].

The clinical follow-up period of the present study may be considered a limitation, however, the divulgation of results is important for comparison with similar follow-up studies [14, 33]. Longitudinal clinical follow-ups for longer periods are necessary to evaluate the influence of different application protocols of the universal adhesive system (Scotchbond Universal) on the clinical behavior of Class I and II composite resin restorations. The datasets generated during the current study are available in the Federal University of Goiás Repository [41].

\section{Conclusions}

It was concluded that the application protocols of the Scotchbond Universal adhesive system did not influence the clinical behavior of Class I and II composite resin restorations during the follow-up period $(15.8 \pm 2.7$ months); and, the adapted FDI and adapted USPHS clinical evaluation criteria were similar to each other.

\section{Abbreviations \\ 10-MDP: 10-methacryloyloxydecyl dihydrogen phosphate; CONSORT: Consolidated Standards of Reporting Trials; ER: Etch-and-rinse: FDI: Fédération Dentaire Internationale/World Dental Federation; MDP-Ca salt: metacriloiloxidecil dihidrogênio fosfato-cálcio; ReBEC: Brazilian Registry of Clinical Trials; SE: Self-Etch; SEE: Selective Enamel Etch; T1: first evaluation; T2: second evaluation; USPHS: United States Public Health Service}

\section{Acknowledgements}

The authors thank to 3M ESPE for providing the adhesive system and composite resins.

\section{Authors' contributions}

AAC, MML, JKMZ and TJEB performed the screening procedures and restorative procedures, being that AAC was a major contributor in writing the manuscript. CABCMN performed the radiographic examinations and reports for initial diagnosis. EMT performed the statistical analysis of the data obtained. GCF and LGL were the evaluators during the clinical evaluations, in addition to that LGL was the guideline of the work. All authors read and approved the final manuscript.

\section{Funding}

The study was financed by the research fomentation agency FAPEG (Foundation for Research Support of the State of Goiás) through a scholarship grant. The funding agencies were not involved in the design of the study; the collection, analysis, and interpretation of data; or in writing the manuscript.

The scholarship was for a single postgraduate student, in the monthly amount of R\$2000.00 (two thousand reais). It started in June 2015 and ended in April 2018

\section{Availability of data and materials.}

The datasets generated during the current study are available in the Federal University of Goiás Repository [Federal University of Goiás Repository. Goiânia, Goiás. 2018. http://repositorio.bc.ufg.br/tede/handle/tede/8506. The dataset used is also available from the corresponding author on reasonable request.

Ethics approval and consent to participate.

This study was approved by the Research Ethics Committee (CAAE: 36829814.0.0000.5083), registered in the Brazilian Registry of Clinical Trials (ReBEC - http://www.ensaiosclinicos.gov.br; RBR-9p3hdp). Written informed consent to participate was obtained from all study participants.

Consent for publication

Not applicable.

Competing interests.

The authors declare that they have no competing interests.

Received: 28 February 2019 Accepted: 20 September 2019

Published online: 21 November 2019

\section{References}

1. Salvio LA, Di Hipólito V, Martins AL, De Goes MF. Hybridization quality and bond strength of adhesive systems according to interaction with dentin. Eur J Dent. 2013;7(3):315-26. https://doi.org/10.4103/1305-7456.115416.

2. Van Meerbeek B, Perdigão J, Lambrechts P, Vanherle G. The clinical performance of adhesives. J Dent. 1998;26(1):1-20.

3. Perdigão J, Dutra-Corrêa M, Saraceni CH, Ciaramicoli MT, Kiyan VH, Queiroz CS. Randomized clinical trial of four adhesion strategies: 18-month results. Oper Dent. 2012;37:3-11. https://doi.org/10.2341/11-222-C.

4. Tay FR, Pashley DH. Aggressiveness of contemporary self-etching systems. I: depth of penetration beyond dentin smear layers. Dent Mat. 2001;17:296-308.

5. Vermelho PM, Reis AF, Ambrosano GMB, Giannini M. Adhesion of multimode adhesives to enamel and dentin after one year of water storage. Clin Oral Invest. 2016. https://doi.org/10.1007/s00784-016-1966-1.

6. Wagner A, Wendler M, Petschelt A, Belli R, Lohbauer U. Bonding performance of universal adhesives in different etching modes. J Dent. 2014;42:800-7. https://doi.org/10.1016/j.jdent.2014.04.012.

7. Marchesi G, Frassetto A, Mazzoni A, Apolonio F, Diolosa M, Cadenaro M, Di Lenarda R, Pashley DH, Tay F, Breschi L. Adhesive performance of a multimode adhesive system: 1-year in vitro study. J Dent. 2014;42:603-12. https:// doi.org/10.1016/j.jdent.2013.12.008.

8. Cuevas-Suárez CE, da Rosa WLO, Lund RG, Silva AF, Piva E. Bonding performance of universal adhesives: an update systematic review. J Dent. 2019;21(7):7-26. https://doi.org/10.3290/j.jad.a41975.

9. Geerts S, Bolette A, Seidel L, Guéders A. An in vitro evaluation of leakage of two etch and rinse and two self-etch adhesives after thermocycling. Int J Dent. 2012:1-7. https://doi.org/10.1155/2012/852841.

10. Giannini M, Makishi P, Ayres APA, Vermelho PM, Fronza BM, Nikaido T, Tagami J. Self-etch adhesive systems: a literature review. Braz Dent J. 2015; 2(1):3-10. https://doi.org/10.1590/0103-6440201302442. 
11. Grégoire G, Sharrock P, Prigent Y. Performance of a universal adhesive on etched and non-etched surfaces: do the results match the expectations? Mat Scien Eng. 2016;C66:199-205. https://doi.org/10.1016/j.msec.2016.04.022.

12. Jang J-H, Lee MG, Woo SU, Lee CO, Yi J-K, Kim D-S. Comparative study of the dentin bond strength of a new universal adhesive. Dent Mat J. 2016; 35(4):606-12. https://doi.org/10.4012/dmj.2015-422.

13. Mena-Serrano A, Kose C, Paula EA, Tay LY, Reis A, Loguercio AD, Perdigão J. A new universal simplified adhesive: 6-month clinical evaluation. J Esthet Restor Dent. 2013;25:55-69. https://doi.org/10.1111/jerd.12005.

14. Perdigão J, Kose C, Mena-Serrano AP, De Paula EA, Tay LY, Reis A, Loguercio AD. A new universal simplified adhesive: 18-month clinical evaluation. Oper Dent. 2014;39(2):113-27. https://doi.org/10.2341/13-045-C.

15. Lawson NC, Robles A, Fu C-C, Lin CP, Sawlani K, Burgess JO. Two-year clinical trial of a universal adhesive in total-etch and self-etch mode in noncarious cervical lesions. J Dent. 2015;43(10):1229-34. https://doi.org/10.1016/ j.jdent.2015.07.009.

16. Lopes LS, Calazans FS, Hidalgo R, Buitrago LL, Gutierrez F, Reis A, Loguercio $A D$, Barceleiro MO. Six-month follow-up of cervical composite restorations placed with a new universal adhesive system: a randomized clinical trial. Oper Dent. 2016;41(5):465-80. https://doi.org/10.2341/15-309-C.

17. Masarwa N, Mohamed A, Abou-Rabii I, Zaghlan RA, Steier L. Longevity of self-etch dentin bonding adhesives compared to etch-and-rinse dentin bonding adhesives: a systematic review. J Evid Base Dent Pract. 2016:96106. https://doi.org/10.1016/j.jebdp.2016.03.003.

18. Purk JH, Dusevich V, Glaros A, Eick JD. Adhesive analysis of voids in class II composite resin restorations at the axial and gingival cavity walls restored under in vivo versus in vitro conditions. Dent Mater. 2007;23(7):871-7. https://doi.org/10.1016/j.dental.2006.07.001.

19. Cvar JF, Ryge G. Reprint of criteria for the clinical evaluation of dental restorative materials. Clin Oral Invest. 2005;9:215-32. https://doi.org/10.1007/ s00784-005-0018-z

20. Hickel R, Peschke A, Tyas M, Mjör I, Bayne S, Peters M, Hiller K-A, Randall R, Vanherle G, Heintze SD. FDI world dental federation: clinical criteria for the evaluation of direct and indirect restorations-update and clinical examples. Clin Oral Invest. 2010;14:349-66. https://doi.org/10.1007/s00784-010-0432-8.

21. Antczak-Bouckoms AA, Tulloch JF, Berkey CS. Split-mouth and cross-over designs in dental research. J Clin Periodontol. 1990;17(7 Pt 1):446-53.

22. Schwendicke F, Göstemeyer G, Blunck U, Paris S, Hsu L-Y, Tu Y-K. Directly placed restorative materials: review and network meta-analysis. J Dent Res. 2016:95(6):613-22. https://doi.org/10.1177/0022034516631285.

23. Suma NK, Shashibhushan KK, Reddy WS. Effect of dentin disinfection with $2 \%$ chlorhexidine gluconate and $0.3 \%$ iodine on dentin bond strength: an in vitro study. Int J Clin Pediatr Dent. 2017;10(3):223-8. https://doi.org/10. 5005/jp-journals-10005-1440.

24. Farhadpour H, Sharafeddin F, Akbarian S, Azarian B. Combination effect of hemostatic and disinfecting agents on micro-leakage of restorations bonded with different bonding systems. J Dent Biomater. 2016;3(3):292-8.

25. Alves dos Santos R, Lima EA, Montes MAJR, Braz R. Pre-treating dentin with chlorhexidine and CPP-ACP: self-etching and universal adhesive systems. Acta Biomater Odontol Scand. 2016;2(1):79-85. https://doi.org/10.1080/ 23337931.2016.1203265.

26. Montagner AF, Sarkis-Onofre R, Pereira-Cenci T, Cenci MS. MMP inhibitors on dentin stability: a systematic review and meta-analysis. J Dent Res. 2014; 93(8):733-43. https://doi.org/10.1177/0022034514538046.

27. Zheng $P$, Zaruba $M$, Attin $T$, Wiegand $A$. Effect of different matrix metalloproteinase inhibitors on microtensile bond strength of an etch-andrinse and a self-etching adhesive to dentin. Oper Dent. 2015;40(1):80-6. https://doi.org/10.2341/13-162-L.

28. Favetti M, Schroeder T, Montagner AF, Correa MB, Pereira-Cenci T, Cenci MS. Effectiveness of pre-treatment with chlorhexidine in restoration retention: a 36-month follow-up randomized clinical trial. J Dent. 2017;60:44-9. https:// doi.org/10.1016/j.jdent.2017.02.014.

29. Flury S, Peutzfeldt A, Schmidlin PR, Lussi A. Exposed dentin: influence of cleaning procedures and simulated pulpal pressure on bond strength of a universal adhesive system. PLoS One. 2017;12(1):e0169680. https://doi.org/ 10.1371/journal.pone.0169680.

30. Mokhtari F, Anvar E, Mirshahpanah M, Hemati H, Kazemi AD. The probable effect of irrigation solution and time on bond strength to coronal dentin: an in vitro evaluation. Iranian Endod J. 2017;12(4):439-42. https://doi.org/10. 22037/iej.v12i4.10106.
31. Fujiwara S, Takamizawa T, Barkmeier WW, Tsujimoto A, Imai A, Watanabe $H$, et al. Effect of double-layer application on bond quality of adhesive systems. J Mech Behav Biomed Mater. 2018;77:501-9. https://doi.org/10. 1016/j.jmbbm.2017.10.008

32. Loguercio AD, de Paula EA, Hass V, Luque-Martinez I, Reis A, Perdigão J. A new universal simplified adhesive: 36-month randomized doubleblind clinical trial. J Dent. 2015;43(9):1083-92. https://doi.org/10.1016/j. jdent.2015.07.005

33. Loguercio AD, Luque-Martinez IV, Fuentes S, Reis A, Muñoz MA. Effect of dentin roughness on the adhesive performance in non-carious cervical lesions: a double-blind randomized clinical trial. J Dent. 2018:69:60-9. https://doi.org/10.1016/j.jdent.2017.09.011

34. Lopes LG, Cefaly DFG, Franco EB, Mondelli RFL, Lauris JRP, Navarro MFL. Clinica evaluation of two "packable" posterior composite resins: two-year results. Clin Oral Invest. 2003;7:123-8. https:/doi.org/10.1007/s00784-003-0218-3.

35. Marques IP, Oliveira FBS, Souza JGS, Ferreira RC, Magalhães CS, França FMG, Popoff DAV. Influence of surface treatment on the performance of siloranebased composite resin in class I restorations: a randomized clinical trial. Clin Oral Invest. 2018. https://doi.org/10.1007/s00784-018-2390-5.

36. Baracco B, Fuentes MV, Ceballos L. Five-year clinical performance of a silorane- vs a methacrylate-based composite combined with two different adhesive approaches. Clin Oral Invest. 2016;20:991-1001. https://doi.org/10. 1007/s00784-015-1591-4

37. Van Dijken JWV, Pallesen U. Durability of a low shrinkage TEGDMA/HEMAfree resin composite system in class II restorations. A 6-year follow up. Dent Mat. 2017;33:944-53. https://doi.org/10.1016/j.dental.2017.04.021.

38. Jacker-Guhr S, Sander J, Luehrs AK. How "universal" is adhesion? Shear bond strength of multi-mode adhesives to enamel and dentin. J Adhes Dent. 2019;21(1):87-95. https://doi.org/10.3290/j.jad.a41974

39. da Rosa WLO, Piva E, Silva AF. Bond strenght of universal adhesives: a systematic review and meta-analysis. J Dent. 2015;43:765-76. https://doi.org/ 10.1016/j.jdent.2015.04.003.

40. Swift EJ Jr, Rittern AV, Heymann HO, Sturdevant JR, Wilder AD Jr. 36-month clinical evaluation of two adhesives and microhybrid resin composites in class I restorations. Am J Dent. 2008;21(3):148-52.

41. Federal University of Goiás Repository. Goiânia, Goiás. 2018. http:// repositorio.bc.ufg.br/tede/handle/tede/8506. .

\section{Publisher's Note}

Springer Nature remains neutral with regard to jurisdictional claims in published maps and institutional affiliations.

Ready to submit your research? Choose BMC and benefit from:

- fast, convenient online submission

- thorough peer review by experienced researchers in your field

- rapid publication on acceptance

- support for research data, including large and complex data types

- gold Open Access which fosters wider collaboration and increased citations

- maximum visibility for your research: over $100 \mathrm{M}$ website views per year

At $\mathrm{BMC}$, research is always in progress.

Learn more biomedcentral.com/submission 